\title{
Teocomunicação
}

Programa de Pós-Graduação em Teologia

Escola de Humanidades

Porto Alegre, v. 47, n. 1, p. 26-38, janeiro-junho 2017

\section{Causalidade psíquica e a fundamentação da psicologia científica segundo Edith Stein}

\author{
Mental Causality and the Foundation of Scientific Psychology According to Edith Stein
}

\author{
Carolina de Resende Damas Cardoso*, Marina Massimi**
}

\section{RESUMO}

A questão da causalidade permeia os fundamentos das ciências. Em particular, a questão da causalidade psíquica subjaz os fundamentos das diversas abordagens da psicologia atual, ainda que não seja explicitada ou mesmo reconhecida. Recorrer a essa temática pode ajudar a esclarecer questões de cunho epistemológico que delineiam a psicologia científica. Nesse sentido, o objetivo do trabalho é apresentar a concepção de causalidade psíquica presente na obra de Edith Stein (1891-1942), Causalidade Psíquica (2010). Foi utilizado o método de investigação histórica. A autora apresentara críticas à psicologia experimental emergente, que se submetia ao reducionismo psicologista e naturalista ao separar-se da filosofia. Edith Stein defendeu a possibilidade de uma psicologia científica sustentada pela definição (fenomenológica) de pessoa humana. Sua compreensão acerca da causalidade psíquica enquadra a distinção entre as vivências imanentes e as vivências intencionais do fluxo de consciência. Stein diferencia o âmbito dos acontecimentos causais determinísticos daqueles âmbitos das relações de motivação que não são submetidas a conexões deterministas. Conclui-se que somente uma elaboração filosófica rigorosa dos diversos tipos de legalidade às quais o fenômeno psíquico está submetido pode fornecer à Psicologia uma fundamentação válida e autonomia no diálogo com as demais ciências naturais ou culturais.

Palavras-Chave: Causalidade psíquica. Psicologia científica. Edith Stein.

\section{ABSTRACT}

The question of causality pervades the foundations of science. In particular, the question of psychic causality underlies the foundations of the various approaches of present psychology, although it is not explicit or even recognized. Resort to the theme can help to clarify epistemological issues that delineate scientific psychology. In this sense, the objective of the work is to present the conception of psychic causality present in the work of Edith Stein (1891-1942), Psychic Causality (2010). The method of historical investigation was used. The author criticized the emergent experimental psychology, which underwent psychologistic and naturalistic reductionism by separating itself from philosophy. Edith Stein defended the possibility of a scientific psychology sustained by the (phenomenological) definition of the human person. Her understanding of psychic causality fits the distinction between the immanent lived experiences and the intentional lived experiences of the flow of consciousness. Stein differentiates the scope of deterministic causal events from those scopes of motivational relations that are not subjected to deterministic connections. It is concluded that only a rigorous philosophical elaboration of the different types of legality to which the psychic phenomenon is submitted can provide to Psychology a valid foundation and autonomy in the dialogue with the other natural or cultural sciences.

KEYWORDS: Psychic causality. Scientific psychology. Edith Stein.

\footnotetext{
* Doutora em Psicologia Universidade de São Paulo em Ribeirão Preto, SP. E-mail: <cmrdc@hotmail.com>.

**Professora Titular da Universidade de São Paulo em Ribeirão Preto, SP. E-mail: <mmassimi3@yahoo.com>.
} 


\section{INTRODUÇÃO}

O objetivo da pesquisa foi retomar o percurso por meio do qual Edith Stein propôs suas análises a respeito da constituição do objeto psíquico (em específico, em relação ao tema da causalidade psíquica), bem como as consequentes implicações que tais definições possibilitam levantar para as discussões epistemológicas em psicologia atualmente - a discussão sobre seu status científico e sua relação com as demais ciências. Considerando essa busca pela definição do objeto da psicologia, fez-se relevante retomar e aprofundar a questão da causalidade psíquica (que significa a legalidade segundo a qual a psique é estruturada).

Historicamente, sabemos da oposição entre as abordagens que adotam os pressupostos explicativos da causalidade determinística e aquelas que buscam explicações não determinísticas na psicologia. Entretanto, tal questão, de certa forma, é sempre pressuposta na psicologia, quer se afirme um ou outro caminho, porém nunca devidamente esclarecida. O trabalho histórico e filosófico, nesse sentido, buscar esclarecer essa lacuna.

A via fenomenológica e, em especial a fenomenologia de Edith Stein é, de fato, muito fecunda para a realização de uma análise crítica a respeito dos rumos enveredados pela psicologia, tendo em vista que a autora ocupou-se diretamente do tema, considerando em suas análises, a discussão a respeito do ser humano inserido na realidade.

Consideramos, além disso, que a retomada histórica desta discussão, visa a problematização da psicologia atual, que tem se deparado com questionamentos ${ }^{1}$ de natureza filosófica - que permanecem ainda sem uma resolução satisfatória no âmbito científico, apesar de todo o aparato técnico e metodológico logrado há desde mais de um século de seu estabelecimento enquanto área autônoma da filosofia.

\section{O STATUS DA PSICOLOGIA EXPERIMENTAL NOS SÉCULOS XIX E XX}

Tradicionalmente, o campo histórico da psicologia científica considera como marco do surgimento (institucional) dessa disciplina a inauguração do primeiro laboratório de psicologia experimental por Wilhelm Wundt (1832-1920), em Leipzig, no ano de 1879. O projeto para uma psicologia científica de Wilhelm Wundt estava inserido dentro da Weltanschauung (visão de mundo) do autor, que definia o substrato filosófico e epistemológico norteador de sua psicologia. Orientado por ela, Wundt apontou o objeto da nova ciência como sendo as representações mentais conscientes dos sujeitos, a maneira como as mesmas ocorrem e o modo como se estruturam em relação umas às outras, tendo por objetivo o estabelecimento das leis (causais) regentes da experiência interna ${ }^{2}$.

Wundt considerava a referida "experiência" como algo totalizante, ou seja concernente à pessoa como um todo, suas experiências internas e externas; entretanto, para que fosse objeto de estudo de uma ciência empírica (a psicologia), haveria de ser "desmembrada" em experiência mediada (referente aos objetos da experiência) e imediata (referente ao sujeito da experiência). Enfatizando esta divisão, postulou que a psicologia deveria se ocupar da segunda, utilizando os mesmos métodos das ciências naturais, a observação e a experimentação. Wundt acreditava que a psicologia deveria

\footnotetext{
${ }^{1}$ HERGENHAHN, B. R. New introduction to the history of psychology, p. 14.

2 ARAÚUO, S. O projeto de uma psicologia cientifica em Wilhelm Wundt, p. 27.
} 
constituir a base das demais ciências naturais e do espírito, sendo, inclusive, a base da própria filosofia, pelo fato de ter por objeto de estudo os processos psicológicos do sujeito ${ }^{3}$.

Nesse sentido, pode-se afirmar que a fenomenologia proposta por Edmund Husserl e, posteriormente assumida por Edith Stein, surgiu justamente em oposição a tal dualismo, proveniente da separação entre o sujeito e o objeto da experiência. Estando inserida na tradição da filosofia moderna, porém já nas raízes das filosofias contemporâneas ${ }^{4}$, a fenomenologia resgatou o problema filosófico do conhecimento, buscando integrar sujeito e objeto a partir de seu conceito basilar de consciência intencional - uma consciência aberta para apreensão do mundo, capaz de conhecer as coisas em si mesmas. As correntes da psicologia científica vigentes da época, influenciadas pelo movimento do psicologismo (e também pelo neokantismo), ao contrário, partiam do suposto de que somente teríamos acesso às representações mentais (internas e subjetivas), e não aos objetos em si, de modo que o hiato entre sujeito e objeto acabou sendo reforçado - e refletido, por exemplo, no projeto de Wundt.

Os estudos em psicologia experimental ganharam força, principalmente, com as pesquisas de Hermann Lotze (1817-1881), Johannes Müller (1801-1858), Gustav Fechner (1801-1887) e Hermann Von Helmholtz (1821-1894), influenciando uma classe de psicólogos que vieram a seguir na mesma esteira, tais como Hermann Ebbinghaus e o próprio Wundt. Com estes autores, a psicologia tornou-se o estudo experimental das sensações localizadas corporalmente e que constituem a base da experiência, por meio da introspecção experimental, podendo ser analisadas em termos matemáticos em relação aos estímulos físicos que as provocam.

Vemos, dessa forma, como, no contexto alemão do século XIX, a psicologia se tornou ciência da experiência reduzida às sensações, para ser considerada científica, em um contexto claramente herdado do psicologismo - cujas raízes remontam ao empirismo de John Locke (1632-1704). Para o psicologismo, as sensações são o alicerce das representações mentais (conteúdo da consciência), de modo que os atos da consciência (como a percepção, recordação, imaginação, etc.) são compreendidos também enquanto meros conteúdos psíquicos, ou seja, "produtos" do funcionamento do psiquismo.

O naturalismo filosófico ${ }^{5}$, também vigente no século XIX - e o decorrente reducionismo da psicologia - foi a consequência lógica do psicologismo, pois, segundo o mesmo postula, se todos os atos da consciência são instâncias psíquicas, as mesmas podem ser explicadas de acordo com modelos teóricos da biologia, mais especificamente, podem ser explicados pela fisiologia cerebral. Outra consequência do naturalismo e do psicologismo, poderíamos dizer, foi a desconsideração dos fenômenos sociais, culturais e históricos, na compreensão da subjetividade humana ${ }^{6}$; ou a redução dos mesmos a meros produtos do psiquismo humano.

Por outro lado, alguns psicólogos do final do século XIX e início do século XX, já apontavam que a psicologia científica não se sustentava sobre alicerces científicos, identificando na mesma disciplina a prematura presença de crises, seja devido a sua imensa fragmentação em diversas especialidades já naquela época, seja devido às heranças metafísicas e idealistas da filosofia (por exemplo, WILLY, Rudolf, 18977). Reflexo dessa crise pode ser encontrado na seguinte afirmação de outro psicólogo

\footnotetext{
${ }^{3}$ ARAÚJO, S. O projeto de uma psicologia cientifica em Wilhelm Wundt. p. 27.

${ }^{4}$ PORTA, M. A polêmica em torno ao psicologismo de Bolzano a Heidegger. p. 114.

${ }_{5}^{5}$ SANTOS, J. Do empirismo à fenomenologia. p.39.

${ }^{6}$ Devemos destacar aqui a exceção de Wundt, com seus estudos sobre a Völkerpsychologie.

${ }^{7}$ MÜlBERGER, A. A psicologia, uma ciência em crise? p. 240.
} 
experimental, Constantin Gutberlet (1837-1928): "não existe um resultado sequer da observação experimental que seja reconhecido de forma universal por todas as escolas em atuação neste campo. Mesmo entre os membros de uma mesma escola ou grupo pouco consenso se pode encontrar"s.

A discórdia entre os psicólogos experimentais também se estendia na discussão acerca da relevância da metafísica. Enquanto esta disciplina filosófica era considerada por alguns como a origem dos problemas epistemológicos da psicologia (por exemplo, em Rudolf Willy, Wilhelm Wundt ${ }^{9}$, Hugo Münsterberg e George Elias Müller ${ }^{10}$ ), outros psicólogos viam nela a possibilidade de complementação da ciência empírica (como William Stern ${ }^{11}$ e Constantin Gutberlet).

Edmund Husserl, por sua vez, ciente dos problemas epistemológicos que a psicologia enfrentava - devido ao distanciamento da filosofia e à apropriação acrítica do método das ciências naturais - opôs-se contundentemente ao psicologismo, cuja proposta, em última instância, deteria a própria lógica e a epistemologia aos condicionamentos de uma ciência que não conseguia definir o seu próprio fundamento. Há de se salientar que o psicologismo formava a base para uma teoria do conhecimento na qual sujeito e objeto resultariam cindidos, de maneira que esta concepção se relacionava justamente com a busca da psicologia em aderir ao modelo das ciências naturais. Husserl, contudo, identificava em tal cisão a fenda sobre a qual a psicologia buscava ineficazmente sustentar seus postulados. Como sintetiza Massimi 12, "historicamente, um conhecimento baseado em um dualismo artificial impossibilitou, segundo Husserl, a construção de uma psicologia capaz de apreensão correta e abrangente da subjetividade e dos fenômenos dela decorrentes".

O "dualismo artificial" apontado por Massimi denota o resultado da separação entre natureza e espírito (posteriormente reduzido a apenas "psique", pela epistemologia positivista e naturalista, considerada em sua conotação mecanicista) historicamente colocado a partir da Idade Moderna. No século XIX foi expressiva a distinção entre ciências da natureza e ciências da cultura - também chamadas ciências do espírito -, em última instância, provocada por esta cisão.

\section{EDITH STEIN E A DEFINIÇÃO DE SUBJETIVIDADE}

Edith Stein, que estudara psicologia com William Stern nos anos de 1911-1912, revelou sua decepção com a disciplina que, segundo nos relata, não conseguia forjar um aparato conceitual consistente que garantisse sua autonomia científica. Por outro lado, encontrara na fenomenologia uma base mais concreta a partir da qual era capaz de enfrentar as questões que, para ela, permaneciam sem resposta na psicologia. Segundo seus relatos, os problemas epistemológicos da psicologia, antes de terem suas raízes na experimentação científica - que se trata apenas de um método -, emergiam da falta de clareza acerca do objeto visado. Esta falta de clareza advinha, em última instância, de questões filosóficas colocadas ao longo da Idade Moderna.

\footnotetext{
${ }^{8}$ MÜLBERGER, A. A psicologia, uma ciência em crise? p. 240

${ }^{9}$ Segundo Araújo (2010), Wundt considerava que o atraso da psicologia em relação às ciências naturais devia-se à grande confusão existente entre os problemas de ordem metafísica e aqueles da alçada psicológica. Não que ele desconsiderasse o importante papel da metafísica. Contudo, para o autor, a psicologia não deveria se ocupar "de questões [metafísicas] acerca da natureza e origem da alma [...]. São assuntos que não podem ser tratados cientificamente, cujas respostas nos levam a girar continuamente em círculo e, portanto, à estagnação. O modelo de referência [para a ciência psicológica] permanece sendo a ciência natural." (ARAÚJO, 2010, p. 35).

${ }^{10}$ Hugo Münsterberg (1863-1916) e George Elias Müller (1850-1934) são citados por Stein (2010c e 2010a, respectivamente).

${ }^{11}$ SCHMIDT, Dialogue with a human scientist; 1997; PAOLINELLI, M. La ragione salvata.

${ }^{12}$ MASSIMI, M. As relações entre psicologia e cultura no horizonte da psicologia moderna e contemporânea, p. 94.
} 
Por esta razão, em sua obra Introdução à Filosofia, partindo da proposta fenomenológica, Stein buscou lançar luzes sobre questões acerca do problema filosófico do conhecimento - temática chave da filosofia moderna e que diz respeito à indagação: "como é possível conhecer alguma coisa?"; e "que estrutura permite tal empreendimento?". Este tema, portanto, suscita questões sobre a estrutura ontológica do sujeito cognoscente. Sendo assim, nesta mesma obra, Stein buscou enfrentar as demais questões referentes à natureza da pessoa, suas semelhanças e diferenças em relação aos outros animais; a definição de subjetividade; a evidenciação da estrutura espiritual humana, contemplando a questão da liberdade e da volição, assim como sua relação com os aspectos psíquicos (cognitivos e afetivos) e sensíveis; a unidade essencial psicofísica e espiritual da pessoa; a constituição do caráter a partir do núcleo anímico; o conhecimento de outras pessoas e de si mesmo; e a ação do homem no mundo. Nesta mesma obra, a autora também analisou outras questões epistemológicas referentes às ciências da subjetividade, por exemplo, a definição do objeto e do método mais adequado da fisiologia, psicologia e ciências humanas além da filosofia, as possibilidades de interdisciplinaridade entre as mesmas e a observação à autonomia de cada área.

Há de se salientar, contudo, que a abordagem de Stein a respeito do tema da definição de pessoa humana foi influenciada por especificidades históricas na qual a autora estava inserida. Nesse sentido, cabe ressaltar o fato de que a análise de algumas dessas questões citadas acima, deve levar em conta o entendimento do cenário filosófico e psicológico a partir do qual a filósofa demarcara seu posicionamento, inserido, inclusive, no tecido sócio-cultural da época ${ }^{13}$. A passagem do século XIX ao XX assistiu a uma revisão de modelos filosóficos: por um lado, a queda do idealismo hegeliano, a necessidade de uma nova fundamentação para a ciência e teoria do conhecimento de modo geral; por outro lado, com a expansão da revolução industrial, a ascensão do modelo positivista e a promessa de progresso que a ciência oferecia.

Além disso, especificamente no contexto da Alemanha, o país havia sido recentemente unificado, sendo constituído o Império Germânico, em 1871. A mínima tolerância da sociedade alemã em relação aos judeus também constitui um aspecto cultural relevante a ser enfatizado, fato citado por Stein em sua autobiografia ${ }^{14}$. O conflito mundial iniciado em 1914 e todas as mudanças - políticas, sociais, econômicas - decorrentes do mesmo, contudo, irão influenciar de maneira radical o subsequente posicionamento da autora até mesmo diante de questões filosóficas - a respeito de seu interesse sobre o tema da empatia, por exemplo. Por esta razão, pode-se afirmar que as análises de Stein enquanto sujeito histórico, inserida num determinado contexto histórico - em relação ao tema da pessoa humana refletiram sua preocupação com o sujeito real e a atuação do mesmo em seu mundo circundante.

No exercício da filosofia, sendo orientada pelo método fenomenológico, Stein apresentou uma concepção de subjetividade que compreende a própria corporeidade e a manifestação anímica da personalidade - em sua constituição psíquica e espiritual. Esta definição do conceito de subjetividade constitui um objeto temático de suma relevância à psicologia científica atual, que tem se voltado cada vez mais a pressupor a pessoa como ser biopsicossocial, em uma pluralidade cada vez maior de abordagens, sem, contudo, aprofundar o significado que este termo reivindica. Uma das finalidades da filosofia, segundo Stein $^{15}$, é justamente esclarecer às ciências aquilo que as mesmas já pressupõem na definição de seus modelos teóricos.

${ }^{13}$ MACINTYRE, A. Edith Stein. p. 161.

${ }^{14}$ STEIN, E. Aus dem Leben einer jüdischen Familie.

${ }^{15}$ STEIN, E. Introduccion a la Filosofía. 
Se considerarmos outros escritos de Stein deste período, juntamente com esta sua obra "Contribuições para a fundação filosófica da psicologia e das ciências do espírito"16, tal como sua tese doutoral defendida em 1917 ("Sobre o Problema da Empatia"17), "Introdução à Filosofia" e a obra "Estrutura da Pessoa Humana"18, podemos encontrar nelas uma apresentação bastante completa da constituição do objeto da psicologia, bem como apontamentos precisos sobre os métodos por ela utilizados e as relações com as demais ciências empíricas. Podemos citar aqui a necessidade de métodos que contemplem a variedade das vivências humanas, de modo que a ciência psicológica possa considerar o caráter mecânico da psique, mas também as conexões de sentido que a constitui. Neste ponto, enfatiza-se, a premência de uma abertura das diversas escolas psicológicas no diálogo umas com as outras e também com as outras ciências, sejam elas naturais ou humanas.

Na obra "Sobre o problema da empatia" Stein define essa vivência como ato intencional da consciência que proporciona as condições para o conhecimento das outras pessoas e também a base para o conhecimento intersubjetivo do mundo. Baseado na percepção, esse ato intencional nos possibilita reconhecer outras pessoas em suas respectivas vidas espirituais e psicológicas. Por meio da empatia é possível reconhecer a experiência corpórea (corporeidade) de outras pessoas, como uma encarnação viva repleta de significado. Esse reconhecimento é o movimento inicial da apreensão empática, que permite a subsequente coapreensão da intencionalidade dos atos de outras pessoas e, portanto, fundamental nas considerações metodológicas da psicologia.

Por sua vez, em sua obra "Introdução à Filosofia", a ênfase recai na definição de subjetividade alicerçada na unidade entre a experiência interna e externa. A fundamentação filosófica proposta por Edith Stein acerca do conceito de subjetividade foi resultado de sua análise fenomenológica minuciosa sobre a estrutura essencial da natureza e possibilidade de apreensão/conhecimento da mesma. A subjetividade, segundo a filósofa, compreende a constituição tripartida da pessoa humana, em seu aspecto corpóreo, psíquico e espiritual, de modo que o corpo vivo, uma estrutura que faz parte da natureza, evidencia a unidade entre o corpo físico e a psique, a experiência interna e a externa dos organismos - temática presente também na "Estrutura da Pessoa Humana". A subjetividade, entretanto, não se limita à constituição do corpo vivo, mas é fruto também da presença indelével do espírito humano, responsável pela modulação daquilo que torna as pessoas o que elas são, ou seja, o caráter/personalidade de um indivíduo. Por esta razão, não se limita apenas ao seu temperamento ou aos comportamentos afetivos e reativos (que também se encontram presentes nos animais), mas é fruto das capacidades de juízo, avaliação/valoração, intencionalidade - ou, voltar-se conscientemente em direção a algo - que o ser humano dispõe de maneira livre.

Finalmente, na obra "Estrutura da Pessoa Humana", Stein não somente retoma e aprofunda as análises anteriormente realizadas acerca da constituição tripartida da Pessoa, mas introduz o tema a partir de suas preocupações com a pedagogia e com as diversas concepções de pessoa que legitimam diferentes práticas pedagógicas. $\mathrm{Na}$ introdução desta obra, Stein afirma que todas as ciências que lidam com pessoas carregam, ainda que de maneira não consciente, uma concepção de Pessoa a partir da qual elaboram e sustentam suas teorias. Isso, é claro, possui implicações nos âmbitos aplicados das ciências. Citando o caso da pedagogia, Stein critica as visões idealista, psicanalista e existencialista, que a norteiam, seja por apresentarem uma visão bastante negativa do

${ }^{16}$ STEIN, E. Beiträge zur philosophischen Begründung der Psychologie und der Geisteswissenschaften.

${ }^{17}$ STEIN, E. Zum Problem der Einfühlung.

${ }^{18}$ STEIN, E. Der Aufbau der menschlichen Person. 
homem e da vida sem horizonte ou esperança (como é o caso das últimas duas), ou positiva demais (como no caso do idealismo) na crença na humanidade - lembremos que Stein publicou essa obra em 1932, década da ascensão do nazismo ao poder e do início da Segunda Grande Guerra (1939); o idealismo alemão, principalmente, segundo a autora, falhara na educação dos jovens. Além disso, nesta obra, Stein se dedica a uma análise do núcleo ou a alma da alma da Pessoa humana. Stein define o núcleo como a origem a partir da qual a vida emerge em sua constituição psicofísica e espiritual. Ele contém em si as metas e a direção para o desenvolvimento da Pessoa e, aponta, portanto, à questão da individuação de um caráter pessoal (ou personalidade).

\section{A RETOMADA DO TEMA DA CAUSALIDADE PSÍQUICA ${ }^{19}$}

Discutir o tema da causalidade psíquica, segundo os próprios apontamentos de Stein em sua obra estava em pauta em inícios do século XX na psicologia. A temática era pertinente, pois resultava no levantamento de importantes questões de ordem metafísica, gnosiológica e científica. Para Stein, estava claro que as discussões sobre a causalidade psíquica orientavam o enfoque admitido e seguido pelas diversas teorias psicológicas que estavam a emergir naquele período. Por um lado, a admissão da esfera psíquica como pertencente unicamente à natureza (e, portanto, partindo-se daí, os problemas referentes às interações entre psique e corpo); por outro lado, questionamentos sobre se a psique admitiria um tratamento específico, tendo em vista a sua constituição própria e, portanto, uma organização em termos de sua natureza específica, com suas conexões necessárias. Tal é o ponto, inclusive, que subjaz às discussões a respeito das conexões, ou seja, o estabelecimento de leis psicofísicas causais necessárias de um lado e o reconhecimento de uma ordenação que admitiria outro tipo de legalidade (necessária ou não) e que possuiria uma legitimidade específica, por outro lado. Stein descreve os princípios associacionistas da psicologia de então como tentativas de legitimar uma legalidade própria do âmbito psíquico, bem como aqueles que se referem ao âmbito da motivação. Essas duas formas de elaboração do acontecer psíquico, contudo, segundo a autora, não esclareciam de maneira definitiva no que consistia o próprio objeto psíquico, deixando, por esta razão, de respaldar o seu próprio fundamento.

As teorias da psicologia também não pareciam demonstrar muita clareza sobre o que era a causalidade em si. As abordagens psicológicas já traziam como pressuposto a busca por uma conexão causal da natureza. Nesse sentido, não se preocupavam em retomar no quê consistia essa relação entre os eventos e, por essa razão, deixavam de verificar se uma explicação causal corresponderia de fato ou não, à estrutura do almejado objeto (psíquico). Nesse sentido, essa temática possuía fundamental relevância para as discussões epistemológicas nas ciências naturais e ciências do espírito.

No texto intitulado Causalidade Psíquica $^{20}$, Stein buscou retomar as análises fenomenológicas sobre a manifestação da causalidade ao nível das vivências da consciência levando em consideração a formação do próprio fluxo contínuo das vivências. O objetivo de sua obra foi analisar como se dá esse fluxo de vivências, o que justifica sua sequência e o que contribui para a permanência das vivências, bem como para o seu eventual desaparecimento do mesmo fluxo.

Ao analisar o fluxo das vivências, Stein afirmou que, em um primeiro momento, a emergência de vivências de diversos gêneros (percepção, audição, recordação,

${ }^{19}$ STEIN, E. Beiträge zur philosophischen Begründung der Psychologie und der Geisteswissenschaften.

${ }^{20}$ STEIN, E. Beiträge zur philosophischen Begründung der Psychologie und der Geisteswissenschaften. p. 5-109. 
sensação de bem-estar) se manifesta como uma associação das mesmas, ainda que não se possa falar em vinculações, mas apenas em manifestações concomitantes. Edith Stein denominou de "associações por contato" (Berührungs-Assoziation) o dar-se das vivências em conjunto. Quando, originalmente, elas emergem juntas, assim também o será em suas posteriores aparições e eventual desaparecimento do fluxo (ou esvaziamento). Constituem, assim, como que um "complexo" de vivências, no qual quando da emergência de alguma, faz com que acompanhe a outra - não de forma aleatória, porém, mas de acordo com a sua manifestação passada. Afirmar a constituição de complexos de vivências no curso do fluxo implica dizer que as mesmas vivências nunca ocorrem de maneira isolada, mas sempre em conformidade com o todo no qual estão originariamente inseridas. Essa é uma informação bastante relevante e possui implicações concretas para a psicologia científica.

De qualquer maneira, as associações por contato não sugerem um tipo de causalidade. A emergência e o fluir de complexos não ocorre segundo uma legalidade causal, mas é expressão do devir próprio da corrente de vivências. Quando surgem, então, as relações causais entre as vivências? Surgem precisamente ao nível da esfera dos sentimentos vitais, quando da influência que os mesmos possuem no transcorrer (total) das vivências. Isso é claramente explicitado quando um sentimento de cansaço influi diretamente ou causa um desbotamento das demais vivências ou, ao invés, um sentimento de alegria faz com que as cores e sons percebidos sejam mais intensos. A mudança, portanto, de um estado vital (por exemplo, o cansaço) gera alteração ao nível das demais vivências.

Esse tipo de causalidade ao nível do vivenciar corresponde, para Stein, ao acontecer causal que ocorre na natureza: é mecânico. Tal como uma bola que se choca com outra determina a direção e velocidade do movimento desta última, o sentimento vital determina o acontecer das demais vivências "não somente a qualidade, mas também a intensidade do efeito depende da causa" ${ }^{21}$. Os outros aspectos da vivência, o seu conteúdo e a consciência que a acompanham, são afetados não de maneira direta pelos estados vitais, mas em conjunto com o vivenciar diretamente influenciado. O conteúdo e a consciência da vivência são, nesse sentido, vitalizados (ganham nova vitalidade ou perdem) em conjunto com o vivenciar.

A discussão apresentada refere-se, contudo, ao nível das vivências puras (visto se tratar de uma análise fenomenológica). Como, então, passar de uma esfera de vivências puras àquela das experiências reais (ou psicológicas)? A esfera dos acontecimentos reais não exerce influência no âmbito das vivências puras. Contudo, as mesmas vivências e os seus conteúdos correspondentes são manifestações de estados e qualidades reais, dos quais os sentimentos vitais também são expressão. Também a causalidade psíquica é manifestada na causalidade fenomênica enquanto qualidade permanente que chega a ser objeto da consciência e, portanto, instância pura. Por sua vez, o âmbito psíquico diz respeito a uma realidade transcendente ao nível da consciência, mas que se manifesta nos conteúdos e nas vivências da esfera da consciência. É importante destacar que a realidade do psíquico não se reduz a condicionamentos dos aspectos físicos, de modo que também a causalidade da esfera psíquica está relacionada com um maior ou menor nível da energia vital. Esta é sempre a mediadora do acontecer psíquico, ou seja, é a causa da alteração de alguma qualidade ou estado da esfera psíquica - isso quer dizer que não há uma interdependência das qualidades e estados da psique entre si, mas a energia vital é sempre a mediadora das alterações ao nível dessas mesmas qualidades e estados. Stein fornece o exemplo: "a receptividade para as cores não pode

${ }^{21}$ STEIN, E. Beiträge zur philosophischen Begründung der Psychologie und der Geisteswissenschaften, p. 16, tradução nossa. 
ser intensificada e nem reduzida pela receptividade para os sons. Mas ambas podem ser intensificadas conjuntamente por meio de uma intensificação, independente de ambas, da energia vital"'22.

Até o momento, foi apresentado um sentido de causalidade que conduz o acontecer ao nível das vivências imanentes à consciência. Contudo, para que haja uma compreensão abrangente da psique, faz-se necessário analisar agora o âmbito das vivências intencionais - as quais Stein denomina por "atos" - ou seja, daquelas vivências cuja constituição depende da presença do $\mathrm{Eu}$. A presença do Eu e, portanto, a mirada intencional que ele leva consigo, designa já outra esfera de vivências, aquela da vida do espírito.

A mirada intencional faz com que o Eu se volte para objetos que se encontram "fora" do fluxo consciência, ou que são transcendentes a ele ${ }^{23}$; ou ainda, transforma em objetos as instâncias constitutivas da própria consciência, seja uma sensação ou um próprio ato, na medida em que também se coloca diante deles (refletindo sobre eles, por exemplo). Percepção, memória e empatia (dentre outros) são exemplos de atos intencionais, pois fazem referência à apreensão de objetos no presente, em "carne e osso", ou o fazem ao se referir ao passado por meio de imagens ou representações. Por se tratarem de um novo gênero de vivências, os atos intencionais requerem a abordagem de um tipo específico de causalidade que sustente a vinculação dos mesmos atos entre si e também com seus respectivos objetos: a motivação.

Pode-se destacar alguns elementos essenciais implicados em toda relação de motivação: a presença do Eu, a vivência motivadora, a vivência motivada e os objetos correlativos das vivências. O principal elemento, contudo, que atua quando da ocorrência de atos motivados relaciona-se com o conteúdo de sentido correlato do primeiro ato. A esse conteúdo, Stein denomina "motivo". É o relâmpago, para citar o exemplo dado por $\operatorname{Stein}^{24}$, que motiva a expectativa do trovão e não a percepção do relâmpago; uma notícia boa motiva o vivenciar de uma alegria, e não o conhecimento dessa notícia, mas a notícia em si. Claro está que o fato de os objetos dos atos constituírem os motivos significa que também os atos a eles correlatos tem um importante papel nas relações de motivação, tanto os atos motivadores (a percepção do relâmpago) quanto os motivados (a expectativa do trovão). É possível afirmar que há entre o motivo e o ato motivado uma conexão de sentido, uma vez que se compreende aquele determinado ato em função do motivo o qual o instigou. Faz-se necessário também pormenorizar as relações estabelecidas entre um e outro, pois a conexão entre ambos pode ou não refletir uma posição racional do Eu que oriente tal conexão. Ademais, um motivo não conduz necessariamente a um determinado ato, mas é possível conceber uma série de possibilidades admissíveis. Nas palavras de $\operatorname{Stein}^{25}$,

Um estado de coisas pode entrar nas conexões lógicas mais diversas e pode permitir, portanto, um número correspondentemente grande de conclusões. Porém, delimita um âmbito de possibilidades e quando o sujeito cognoscente excede esse âmbito, então procede irracionalmente. De igual modo, um valor delimita eventualmente um âmbito de diversas tomadas de posições [reações] possíveis do sujeito que percebe o valor. Pode suceder então que o conteúdo de uma vivência não exija imediatamente um determinado [ato] motivado, mas sim exija um dos diversos [atos] motivados possíveis. Existe ainda outra possibilidade: um motivo vivenciado pode permitir diversas formas de comportamento, sem exigir nenhuma delas.

\footnotetext{
${ }^{22}$ STEIN, E. Beiträge zur philosophischen Begründung der Psychologie und der Geisteswissenschaften, p. 24, tradução nossa.

${ }^{23} \mathrm{Na}$ verdade, os objetos transcendentes somente possuem lugar no fluxo da consciência, justamente por serem correlatos do Eu e do lugar que o Eu ocupa no fluxo.

${ }^{24}$ STEIN, E. Beiträge zur philosophischen Begründung der Psychologie und der Geisteswissenschaften, p. 38.

${ }^{25}$ STEIN, E. Beiträge zur philosophischen Begründung der Psychologie und der Geisteswissenschaften, p. 38-39, tradução nossa, grifos da autora.
} 
Edith Stein introduz aqui a dimensão dos valores, cuja apreensão é fundante do mundo espiritual e das relações de motivação. Os valores são instâncias objetivas que expressam conteúdos de sentido e, portanto, constituem motivos importantes a partir dos quais outros atos intencionais poderão emergir.

\section{COOPERAÇÃO ENTRE CAUSALIDADE E MOTIVAÇÃO}

O fato de os atos participarem do fluxo de vivências da consciência submete-os também a um condicionamento causal, ou seja, fá-los ser dependentes da esfera vital. De fato, ao nível psíquico, o próprio surgimento dos atos depende da disponibilidade da energia vital, bem como o vivenciar dos mesmos. Poderíamos afirmar com isso, por exemplo, que em um estado de cansaço, a mirada intencional ocorre com menor vivacidade. $\mathrm{O}$ desencadear de um ato em outro ocorre via motivação, mas a constituição do ato e o seu vivenciar psíquico são condicionados causalmente, condicionados pela disponibilidade da energia vital ${ }^{26}$.

Stein sugere que existem atos que são dados de fato (sachgebenden Akte) - ou seja, atos que se dirigem para coisas - tais como a percepção, a recordação e os atos do pensamento, os quais são dependentes da esfera vital para emergirem, mas quando ocorrem, não interferem na própria esfera, ou seja, não geram o dispêndio de energia vital e não interferem nos sentimentos vitais. Ela distingue, porém, outros atos cuja emergência se vincula ao âmbito dos sentimentos vitais e que, portanto, quando ocorrem, interferem nesta esfera. São as chamadas emoções (Gemütsbewegungen) ou sentimentos (Gefühle). As emoções e os sentimentos constituem um posicionamento (reação ou atitude) diante dos objetos aos quais estão vinculados, de modo que Stein os caracteriza como tomadas de posição ante os valores (Wertstellungnahmen). Ela cita a alegria (emoção) diante do recebimento de uma boa (valor) notícia (objeto) ${ }^{27}$.

Conforme nos esclarece, tais tomadas de posição ante os valores são condicionados pelo estado disponível da energia vital, de modo que as reações (no caso, a alegria) podem ocorrer com maior ou menor vigor. Desse modo, por exemplo, em um estado de esgotamento, é possível que a alegria não chegue a afetar o sujeito ${ }^{28}$, apesar de o mesmo reconhecer o valor positivo dessa notícia. Os sentimentos vitais vinculados aos valores são, portanto, segundo as palavras de Stein ${ }^{29}$, "uma nova corrente que, desde fora se derrama na corrente vital, a agita e influencia em seu ulterior transcurso, colorindo-a de modo determinado. A índole da influência será distinta de acordo com a índole do sentimento". Nesse sentido, quanto maior for o valor apreendido de um objeto, maior a intensidade (ou profundidade) da vivência do sentimento correspondente a ele.

Em suma, estar diante de um objeto cuja percepção admite a apreensão de um valor a ele vinculado suscita um sentimento que é agregado ao valor apreendido em uma relação de motivação - que, por sua vez, pode ou não ser racional. O objeto percebido é o motivo tanto da emergência do sentimento quanto da apreensão de um valor. Contudo, o sentimento vital correspondente vinculado ao valor percebido do referido objeto emerge a partir de uma relação causal, visto ser condicionado pela energia vital. O conteúdo dos

\footnotetext{
${ }^{26}$ STEIN, E. Beiträge zur philosophischen Begründung der Psychologie und der Geisteswissenschaften. p. 39.

${ }^{27}$ STEIN, E. Beiträge zur philosophischen Begründung der Psychologie und der Geisteswissenschaften, p. 65.

${ }^{28}$ É possível depreender, como viemos apontando até o momento, algumas implicações para a psicologia aplicada e, em especial, para a psicologia clínica. Um quadro clínico de depressão poderia ser compreendido como uma alteração da energia vital, um esgotamento ou uma paralisação da mesma. Outros sintomas, como a mania podem ser caracterizados por uma grande disponibilidade de energia vital e uma grande expansão de impulsos e tendências, porém, com um enfraquecimento do Eu.

${ }^{29}$ STEIN, E. Beiträge zur philosophischen Begründung der Psychologie und der Geisteswissenschaften, p. 65, tradução nossa.
} 
mesmos sentimentos, tal como foi explicitado a respeito dos conteúdos dos impulsos, interferem na energia vital, podendo aumentá-la ou consumi-la.

Por outro lado, atos e ações que ocorram a partir da emergência do sentimento, são por ele motivados. Segundo Stein ${ }^{30}$,

encontram-se constantemente entrelaçados o acontecer causal e o acontecer motivacional: um sentimento que me 'domina' de repente, pode ter efeitos tão paralisadores, que o ato da vontade que esse sentimento deveria motivar 'propriamente', 'razoavelmente' [motivado objetivamente] não seja capaz de surgir absolutamente.

Ou ainda, é possível estar diante de um objeto cujo valor promova descanso e renovação das forças, como é o caso da beleza de um poema. Enquanto o vivenciar mesmo de um sentimento ocasiona dispêndio de energia vital, o conteúdo da mesma vivência, seu valor correspondente, pode atuar na renovação da mesma energia. Isso ocorre quando o conteúdo da vivência é egoico (ichlich Gehalt), ou seja, referente ao Eu. Àquelas vivências que não estão acompanhadas do Eu não possuem essa possibilidade de revitalizar estados anímicos. Ainda nas palavras de Stein ${ }^{31}$,

O que está diante de mim, sem referência ao $\mathrm{Eu}$, como um dado dos sentidos, isso - enquanto conteúdo - não tem nenhuma influência na minha vida. Da mesma maneira, os objetos que adquirem para mim uma objetividade em virtude de tais dados não referentes ao Eu - as 'meras coisas' - não se encontram em conexão alguma com a esfera da atividade psíquica. Por conseguinte, o único que interessa aqui é a 'esfera do ânimo', e como seu correlativo objetivo, o mundo dos valores, das metas práticas e das obras. Entre as vivências dirigidas a objetos e cujos conteúdos consomem energia vital sem renová-la, encontramse o pânico, a angústia e os conflitos [que eventualmente podem paralisar os impulsos e as atividades do Eu].

As chamadas "vivências do ânimo" (Gemütserlebnisse) - que são as emoções e os sentimentos - suscitam tomadas de posição (reações ou atitudes) que, por sua vez, são as fontes para as ações. Vimos que tais vivências são desencadeadas por motivos (conteúdos referentes ao Eu; valores), de modo que podemos dizer que os motivos fornecem energia necessária para a emergência das emoções e dos sentimentos e, portanto, em última instância, fornecem energia (Kraft) também para a realização das ações/atividades suscitadas por essas emoções. É necessário, contudo, certa vitalidade para apreender e vivenciar aqueles conteúdos e, ademais, para a ação (motivada) requerida por ele.

Há, portanto, aqui, a expressão tanto das relações de causalidade quanto as de motivação. Segundo Stein, as primeiras se expressam na transformação de um motivo possível em um motivo real (via energia vivificadora advinda desse mesmo motivo que, de fato, deve converter-se em impulso vivo ou tendência viva para que seja realizado). Em suas palavras, "se o motivo não é vivo, se não promove em mim uma energia vivificadora, então não botará dele uma tendência viva, mas unicamente um conhecimento carente de energia, eventualmente um mero conhecimento de que algo deveria ser assim" 32 .

${ }^{30}$ STEIN, E. Beiträge zur philosophischen Begründung der Psychologie und der Geisteswissenschaften, p. 66, tradução nossa.

${ }^{31}$ STEIN, E. Beiträge zur philosophischen Begründung der Psychologie und der Geisteswissenschaften, p. 68-69, tradução nossa.

${ }^{32}$ STEIN, E. Beiträge zur philosophischen Begründung der Psychologie und der Geisteswissenschaften, p. 69, tradução nossa. 
Por esta razão, a energia necessária para a apreensão de dados sensíveis, por exemplo, é proveniente da vida natural e, portanto, vai requerer um tipo específico de força, a energia vital sensível (sinnliche Lebenskraft). Os dados sensíveis, como já vimos, são imanentes à consciência. Já para a apreensão de conteúdos que se encontram fora da consciência, é necessária uma força específica e ademais, que se lhe seja acrescentada a energia proveniente desses conteúdos transcendentes à consciência (que, como vimos, podem se tratar dos motivos e das tomadas de posição do ânimo que, por sua vez, vitalizam e, portanto, podem acrescer ou diminuir a energia original). Trata-se da energia vital espiritual (geistige Lebenskraft). A energia vital sensível e a energia vital espiritual estão na raiz da psique e são manifestações de uma única energia vital constituinte da dinâmica psíquica.

A energia vital sensível insere-se nas condições de formação das vivências corporais (materiais e em relação com o mundo natural) e, portanto, da corporeidade em si em unidade com a psique. Nas palavras de $\operatorname{Stein}^{33}$, "os estados vitais sensíveis são vivenciados como estados corporais. O frescor e o cansaço aparecem como que inundando o corpo e todos os seus membros, dando colorido às atividades que são dadas corporalmente". É possível diferenciar dos referidos estados corpóreos, o cansaço e o frescor espiritual, que são dados na esfera das vivências espirituais e podem também ser sentidos pelo corpo, porém, são condicionados pelo nível disponível da energia vital espiritual. Dessa forma, pode-se dizer que a energia vital espiritual é condicionada pela energia vital sensível - o contrário não se pode dizer, porém -, uma vez que é sabido que os estados corpóreos podem influenciar na manifestação de vivências espirituais. No entanto, devido à própria constituição da esfera espiritual, sendo ela uma abertura para o mundo externo, a energia vital espiritual também pode estar condicionada por aspectos externos referentes ao mundo dos objetos - incluem-se aí os valores objetivos.

Em suma, levando em consideração a estrutura tripartida da pessoa humana, Stein aprofundou no tema das relações entre os tipos de legalidade que constituem o aspecto psíquico. A autora defendeu a possibilidade de uma psicologia científica sustentada pela definição (fenomenológica) de pessoa humana. Sua compreensão acerca da causalidade psíquica enquadra a distinção entre as vivências imanentes e as vivências intencionais do fluxo de consciência. Nesse sentido, Stein diferencia o âmbito dos acontecimentos causais determinísticos daqueles âmbitos das relações causais que não são submetidas a conexões deterministas. Stein não exclui a legalidade causal na constituição de fenômenos psíquicos e, portanto, na constituição da pessoa humana. Para ela existe o âmbito em que os fenômenos emergem conforme uma legalidade causal, que é o nível dos fenômenos vitais na determinação das vivências imanentes da consciência e outros atos. Outro tipo de legalidade analisada por ela diz respeito à esfera da motivação, que não é determinística, mas que também pode não ser inteiramente racional. $\mathrm{O}$ âmbito das relações de motivação diz respeito à esfera espiritual humana e está em profunda unidade com a dimensão psicofísica.

\section{CONCLUSÃO}

Consideramos que a retomada do tema da causalidade psíquica visa a problematização da psicologia atual, que tem se deparado com questionamentos de natureza filosófica e epistemológica - que permanecem ainda sem uma resolução satisfatória no âmbito científico, apesar de todo o aparato técnico e metodológico logrado há desde mais de

${ }^{33}$ STEIN, E. Beiträge zur philosophischen Begründung der Psychologie und der Geisteswissenschaften, p. 70, tradução nossa. 
um século de seu estabelecimento enquanto área autônoma da filosofia. Edith Stein adverte-nos para uma verdade atemporal a respeito dessa ciência: não há como separála da filosofia sem reduzi-la, por um lado, ao naturalismo cientificista (representado atualmente pelo campo das neurociências) e, por outros, às ciências humanas (hoje orientadas pelos movimentos pós-estruturalistas relativistas). Somente uma elaboração filosófica (rigorosa) do conceito de Pessoa poderá integrar os diversos tipos de legalidade às quais o fenômeno psíquico está submetido, sem reduzir uma à outra e, portanto, fornecer à Psicologia uma fundamentação válida e autonomia no diálogo com as demais ciências naturais ou culturais.

\section{REFERÊNCIAS}

ARAÚJO, Saulo de Freitas. O projeto de uma psicologia cientifica em Wilhelm Wundt: uma nova interpretação. Juiz de Fora: Editora UFJF, 2010.

HERGENHAHN, B. R. New introduction to the history of psychology. Belmont: Wadsworth, 2001. HUSSERL, Edmund. Investigações lógicas. São Paulo: Nova Cultural, 1996. (Original publicado em 1901).

MACINTYRE, Alasdair. Edith Stein - um prólogo filosófico, 1913-1922. Granada: Editorial Nuevo Inicio, 2008.

MASSIMI, Marina. As relações entre psicologia e cultura no horizonte da psicologia moderna e contemporânea. In: MASSIMI, Marina (Org.) Psicologia, Cultura e História: perspectivas em diálogo. Rio de Janeiro: Outras Letras, 2012.

MÜLBERGER, Annette. A psicologia, uma ciência em crise? Visões divergentes entre 1897 e 1911. In: PORTUGAL, Francisco Teixeira; JACÓ-VILELA, Ana Maria (Org.). Clio-Psyché: Gênero, psicologia, história. Rio de Janeiro: Nau Editora, 2012.

PAOLINELLI, Marco. La ragione salvata. Sulla "filosofia Cristiana” di Edith Stein. Milão: Franco Angeli, 2001.

PORTA, Mario Ariel Gonzalez. A polêmica em torno ao psicologismo de Bolzano a Heidegger. Sintese: Revista de Filosofia, Belo Horizonte, v. 31, n. 99, p. 107-131, 2004.

SANTOS, José Henrique. Do empirismo à fenomenologia. A crítica do psicologismo nas Investigações Lógicas de Husserl. São Paulo: Loyola, 2010.

SCHMIDT, Wilfred H. O. Dialogue with a human scientist: William Stern (1871-1938), 1985. Disponível em: <http://ejournals.library.ualberta.ca/index.php/pandp/article/viewFile/14990/11811>. Acesso em: 12 dez. 2012.

STEIN, Edith. Aus dem Leben einer jüdischen Familie und weitere autobiographische Beiträge. Edith Stein Gesamtausgabe - ESGA, v. 1. Freiburg: Herder, 2010. (Original de 1933).

Beiträge zur philosophischen Begründung der Psychologie und der Geisteswissenschaften. ESGA, Band 6. Freiburg im Breisgau: Herder, 2010. (Original de 1922).

Der Aufbau der menschlichen Person. Edith Stein Gesamtausgabe - ESGA, v. 14. Freiburg: Herder, 2010. (Original de 1932).

Introduccíon a la Filosofía. In: STEIN, Edith. Obras completas: Escritos filosóficos etapa fenomenológica, v. II. Burgos: Monte Carmelo; Vitoria: El Carmen; Madrid: Editorial de Espiritualidad, 2005. (Original de 1991, publicação póstuma).

Zum Problem der Einfühlung. Halle: Buchdruckerei des Waisenhauses, 1917.

Recebido em: 30/11/2016

Aprovado em: 16/06/2017

Carolina de Resende Damas Cardoso

Rua Capitão Jarbas Vieira de Souza, 445, apto. 136 - São Luiz

$14020-470$ - Ribeirão Preto - SP - Brasil

Marina Massimi

Universidade de São Paulo

Faculdade de Filosofia, Ciências e Letras de Ribeirão Preto

Av. Bandeirantes, 900 - Cidade Universitária

14040-901 - Ribeirão Preto - SP - Brasil 